\title{
GENERATION OF POLYMER BASES BY THE USE OF PHOTOCHEMICAL REACTION OF POLYMERS BEARING ACYLOXYIMINO GROUPS AND ITS APPLICATION TO UV CURING SYSTEMS
}

\author{
KEN-ICHI ITO,* 1 YOSHITAKA SHIGERU*2 and MASAHIRO TSUNOOKA*2 \\ * 1 Central Laboratory, Rengo Co. Ltd., \\ 1-186, Ohhiraki, 4-chome, Fukusima-ku, Osaka 553, JAPAN \\ * 2 Department of Applied Chemistry, College of Engineering, \\ University of Osaka Prefecture, \\ 1-1, Gakuen-cho, Sakai, Osaka 593, JAPAN
}

Photo-initiated crosslinking of epoxides is very promising from the view point of application to photocurable coating and photoresist.[1] Although amines are known to be useful as crosslinkers for epoxides, only a few studies on the photo-initiated formation of amines are reported. We reported that in the photolysis of copolymers of 0-acryloy1 acetophenone oxime (AAPO) with styrene, pendant acyloxyimino (AOI) groups led to pendant amino groups in a good yie1d [2] and that the pendant amino groups were effective in crosslinking of the pendant epoxy groups in the same polymer.[3] Wi11son et a1. reported that photolysis of a cobalt-ammine complex led to the formation of ammonia which induced the crosslinking of a glycidyl methacrylate - ethyl acrylate copolymer upon heating. [4] Fréchet et a1. reported that photolysis of a,a-dimethy1-3,5dimethoxybenzyl carbamates [5] and o-nitrobenzyl carbamates [6] led to the formation of amines and that resulting amines could be utilized as crosslinkers. Nishikubo et al. utilized amines generated by photolysis of blocked amines as crosslinkers of epoxy resin or polyurethane. [7]

In previous papers [8,9], we have reported that monoamines or diamines are formed efficiently by the photolysis of 0-acyloximes in a polystyrene film and the diamines were more efficient crosslinkers for poly(g1ycidy1 methacrylate) (PGMA) films. However, these amines were not efficient crosslinkers for epoxy resins. In this paper we report thermal crosslinking of epoxy resin by polymer amines formed by the photolysis of AAPO copolymers.

AAPO copolymers were prepared by radical copolymerization of AAPO with ethy1 acrylate (EA) or styrene (St) in benzene using 2,2'-azoisobutyro-nitrile as initiator under vacuum at 60 C. [2] Commercial epoxy resin, EPOLIGHT 100MF 
(trimethylo1 propane triglycidy1 ether, TMPGE, epoxy equivalent: 140) was provided by Kyoueisha Yusi Kagaku Kogyo Co. Ltd. The structures of copolymers and epoxy resin are shown in Fig. 1.<smiles>CCCCCC(CC)C(=O)ON=C(C)c1ccccc1</smiles>

AAPO-St

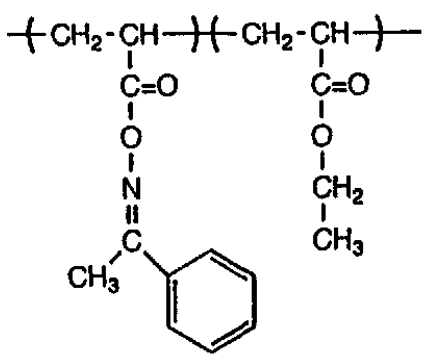

AAPO-EA

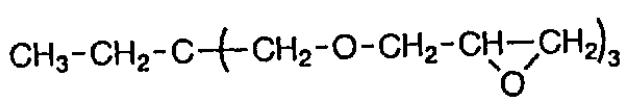

THPGE

Fig. 1. Structures of AAPO copolymers and epoxy resin.

Thin films (ca. $0.15 \mu \mathrm{m}$ thick) of the copolymers with $10 \mathrm{wt} \%$ TMPGE and $10 \mathrm{wt} \%$ benzophenone (BP) as sensitizer were prepared by casting a tetrahydrofuran (THF) solution of the copolymer and additives on a quartz plate $(1 \times 4 \mathrm{~cm})$. The films were irradiated on the quartz plate with a high-pressure mercury lamp (Sen Tokusyu Kogen Co. Ltd., HL-100, $100 \mathrm{~W}$ ) at a distance of $7 \mathrm{~cm}$ at room temperature under air for a given time. After irradiation the films were heated at a given temperature for a given time. Then the films were immersed in THF for $10 \mathrm{~min}$ at room temperature. The insoluble fraction was determined from the thickness of the films before and after the immersion measured using an interference microscope (Nikon OPTIPHOT).

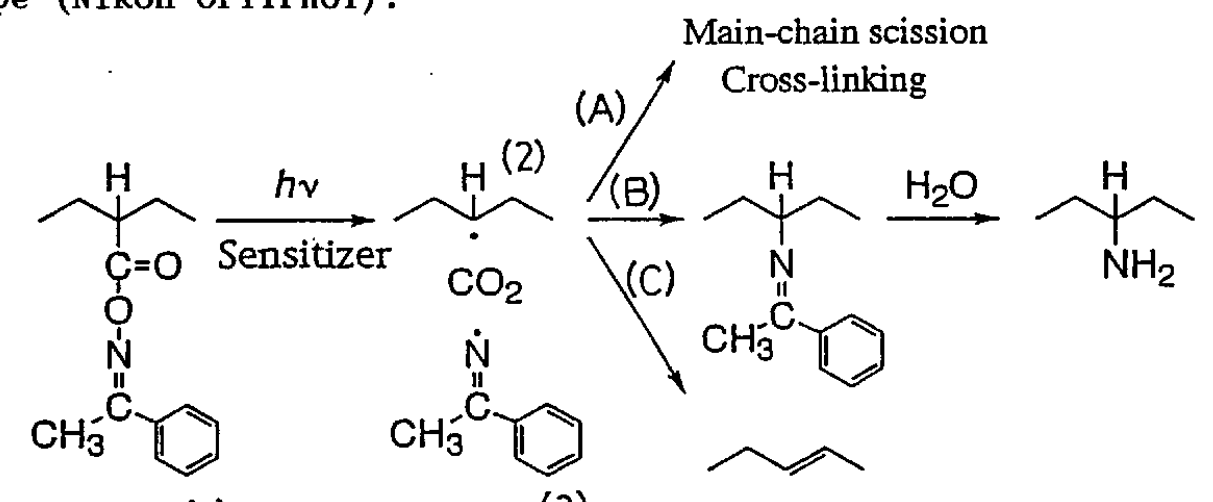

AAPO (1)

(3)

Scheme 1. Photoreaction mechanism of copolymers bearing AOI groups

In the photolysis of AAPO-St copolymers in films pendant AOI groups leads to pendant amino groups as shown in Scheme 1 . The yie1ds of amino groups of AAPO (26.3)-St copolymer were ca. $70 \%$ under air and $N_{2} \cdot$ [2] Therefore, it is expected that the pendant amino groups of AAPO copolymers react with epoxy groups of epoxy resins, which results in crosslinking.

Figure 2 shows the change on the UV spectra of AAPO(34)-St films containing 10 wt\% TMPGE and $10 \mathrm{wt} \%$ BP upon UV irradiation under air. The peak at $248 \mathrm{~nm}$ due to 
AOI groups of the copolymer decreased rapidly with irradiation time.

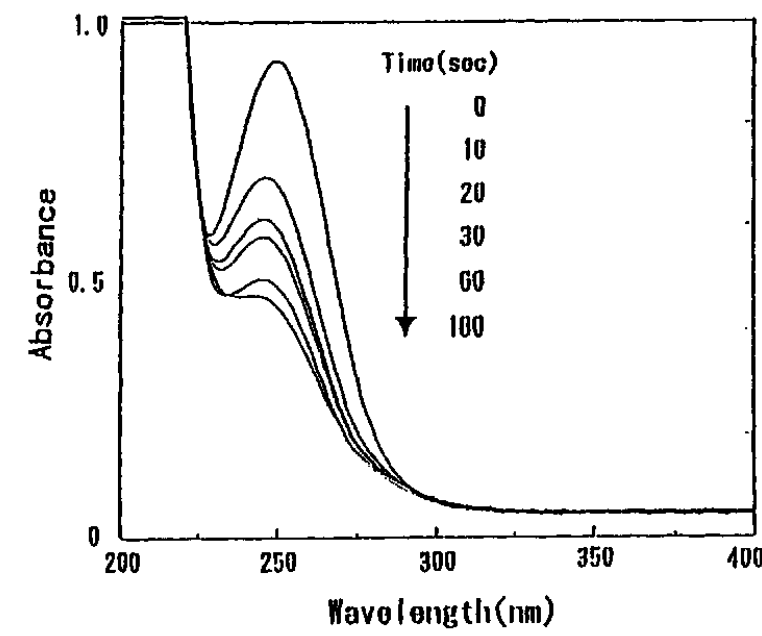

Fig. 2. Change on the UV spectra of AAPO(34)-St film (ca. $0.15 \mu \mathrm{m}$ thick) with $10 \mathrm{wt} \%$ BP and 10 wt\% TMPGE upon UV irradiation under air.

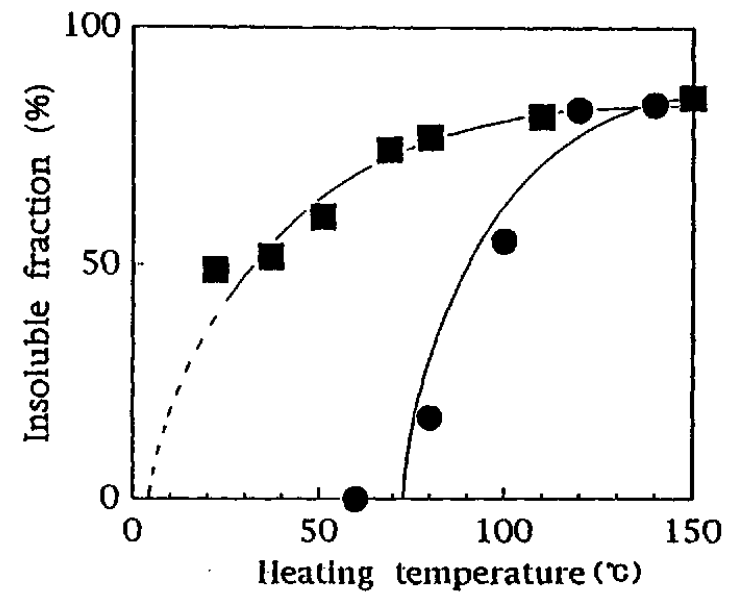

Fig. 3. Relationship between heating temperature and insoluble fraction of AAPO copolymers films with $10 \mathrm{wt} \%$ BP and $10 \mathrm{wt} \%$ TMPGE (ca. $0.15 \mu$ thick):

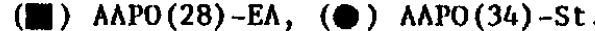

After irradiation for $10 \mathrm{~min}$ under air, heated for $10 \mathrm{~min}$.

Figure 3 shows the relationship between heating temperature after irradiation and insoluble fraction of AAPO copolymers. AAPO(34)-St ( $\overline{\mathrm{M}}=85000, \mathrm{Tg}=93.3 q$ ) films could be insolubilized by heating at a temperature above ca. $70 \mathrm{q}$, while AAPO (28)-EA ( $(\bar{M}=77000, T g=17.3 \Upsilon)$ films could be done at a room temperature and the insoluble fraction of the film reached ca. 50\%. Since local segment motion of main chains in AAPO(28)-EA copolymer occurs at temperatures higher than the $\mathrm{Tg}$ of the copolymer, it is deduced that the reaction of amino groups of the copolymer with epoxy groups of TMPGE occurs efficiently to insolublize the copolymer at the room temperature. This result suggests that the lowering of $\mathrm{Tg}$ of copolymer plays a important role on the curing.

Figure 4 shows the effect of heating temperature on photocrosslinking of AAPO(34)-St films (a) and AAPO(28)-EA films (b). In the case of heating at 150 C after irradiation, both films were insolubilized rapidly at the same rate. The insoluble rate of AAPO(34)-St films fell significantly with lowering of heating temperature, while that of AAPO(28)-EA films did only slightly.

Figure 5 shows the Arrhenius plot of photocrosslinking of AAPO(34)-St and AAPO(28)-EA films. The photocrosslinking rates were determined as the reciprocal of time required for insolubilization of $50 \%$ of the copolymer films in Fig. 3 . The apparent activation energies $\left(E_{a, t}\right)$ of insolubilization for AAPO(34)-St and AAPO(28)-EA films which were caluculated from the plot were $64.3 \mathrm{~kJ} / \mathrm{mol}$ and 21.3 $\mathrm{kJ} / \mathrm{mol}$, respectively. One of causes of lower $E_{a_{c} t}$ of AAPO(28)-EA copolymer is thought to be that the energy required for the segment motion of AAPO(28)-EA copolymer is lower than that of AAPO(34)-St copolymer from the Tgs of both copolymers. Further details are now under investigation. 


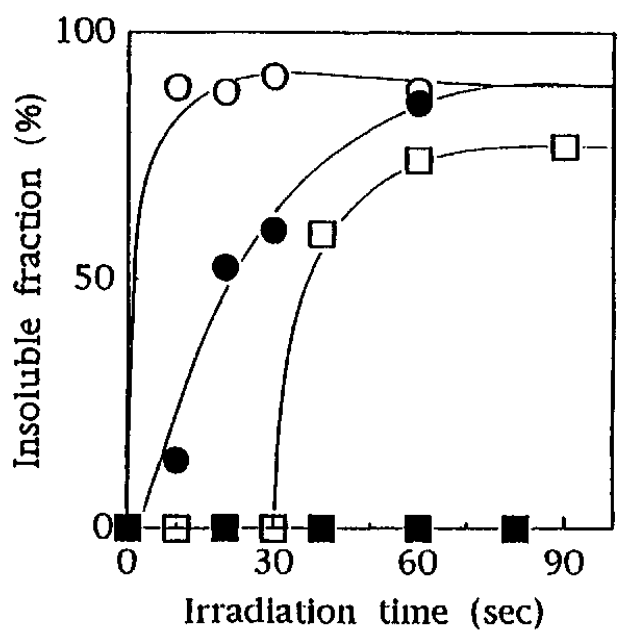

(a)

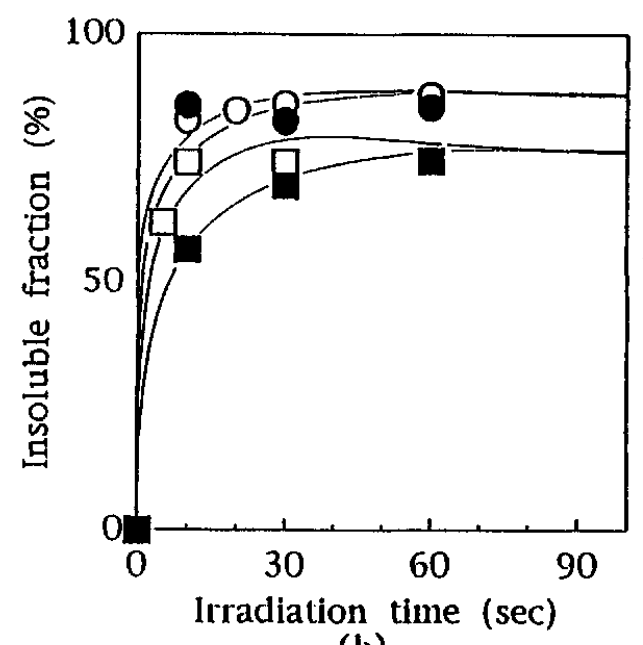

(b)

Fig. 4. Ef fect of heating temperature on photocrosslinking of AAPO(34)-St films (a) and AAPO(28)-EA films (b) with $10 \mathrm{wt} \% \mathrm{BP}$ and $10 \mathrm{wt} \%$ TMPGE

(ca. $0.15 \mu$ thick): (回) $60 \mathrm{r}$, (D) $80 \mathrm{r}$, (O) $100 \mathrm{r}$, (O) $150 \mathrm{r}$. After irradiation under air, heated for $5 \mathrm{~min}$.

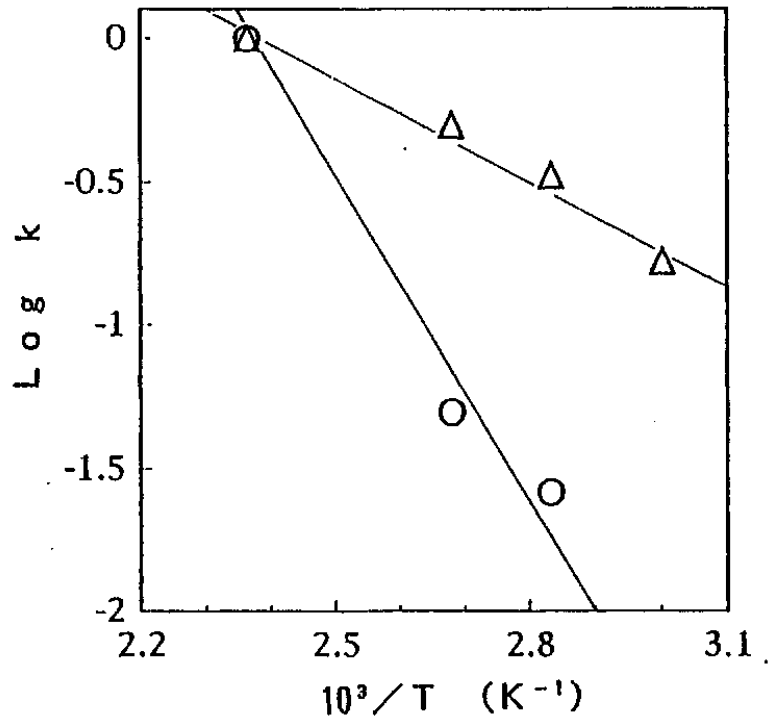

Fig. 5. Arrlenius plot of photocrosslinking of copolymer films (ca. 0.15 fin thick)

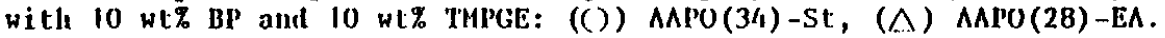
$\kappa$ : Photocrosslinking rate at $50 \%$ of insoluble fraction of copolymer films.

\section{References}

1. J.M.J.Fréchet, Pure App1. Chem., 64 (1992) 1239.

2. K.H.Song, M.Tsunooka and M.Tanaka, J.Photochem.Photobio1., A, 44 (1988) 197.

3. K.H.Song, A.Urano, M.Tsunooka and M.Tanaka, J.Polym.Sci., Part C, Po1ym. Lett., 25 (1987) 417.

4. C.Kuta1 and C.G.Wi11son, J.E1ectrochem.Soc., 134 (1987) 2280.

5. J.F.Cameron and J.M.J.Fréchet, J.Photochem.Photobio1., A, 59 (1991) 105.

6. J.F.Cameron and J.M.J.Fréchet, J.Am.Chem.Soc., 113 (1991) 4303.

7. E.Takehara, A.Kameyama and T.Nishikubo, Polym.J., 25 (1993) 421.

8. K.Ito, M.Nishimura, M.Sashio and M.Tsunooka, Chem.Lett., 1992, 1153.

9. M.Tsunooka and K.Ito, Proc. RadTech Asia'93, Tokyo(1993)p. 187. 